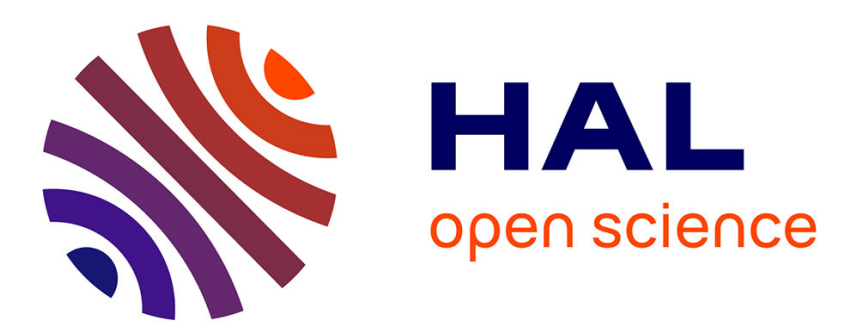

\title{
Affinity adsorbents for proline-rich peptide sequences: a new role for $\mathrm{WW}$ domains
}

\author{
A M G C Dias, A dos Santos, O Iranzo, A C A Roque
}

\section{To cite this version:}

A M G C Dias, A dos Santos, O Iranzo, A C A Roque. Affinity adsorbents for proline-rich peptide sequences: a new role for WW domains. RSC Advances, 2016, 6 (73), pp.68979-68988. 10.1039/C6RA10900D . hal-01477046

\section{HAL Id: hal-01477046 \\ https://hal.science/hal-01477046}

Submitted on 26 Feb 2017

HAL is a multi-disciplinary open access archive for the deposit and dissemination of scientific research documents, whether they are published or not. The documents may come from teaching and research institutions in France or abroad, or from public or private research centers.
L'archive ouverte pluridisciplinaire HAL, est destinée au dépôt et à la diffusion de documents scientifiques de niveau recherche, publiés ou non, émanant des établissements d'enseignement et de recherche français ou étrangers, des laboratoires publics ou privés. 


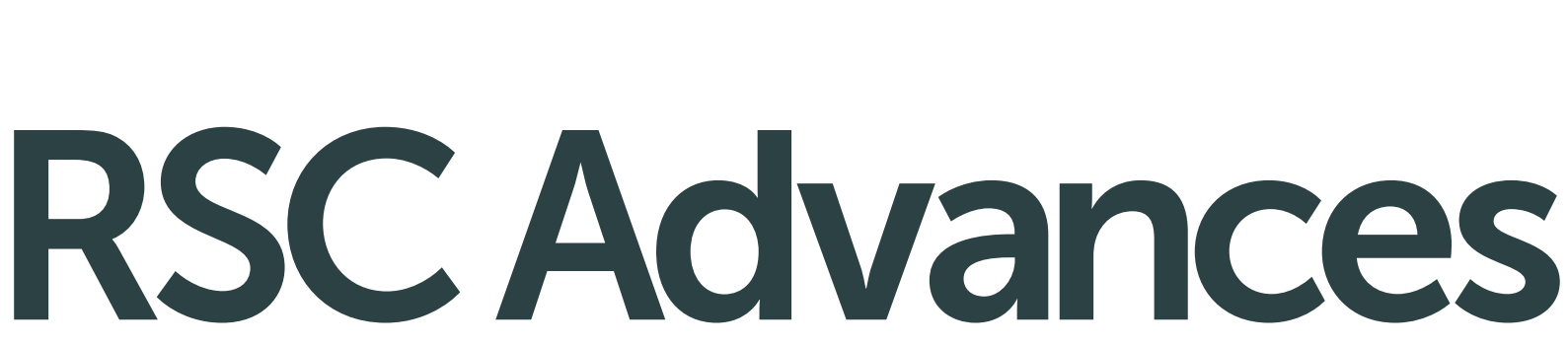

This article can be cited before page numbers have been issued, to do this please use: A. M. Dias, R. dos Santos, O. Iranzo and A. C. A. Roque, RSC Adv., 2016, DOI: 10.1039/C6RA10900D.

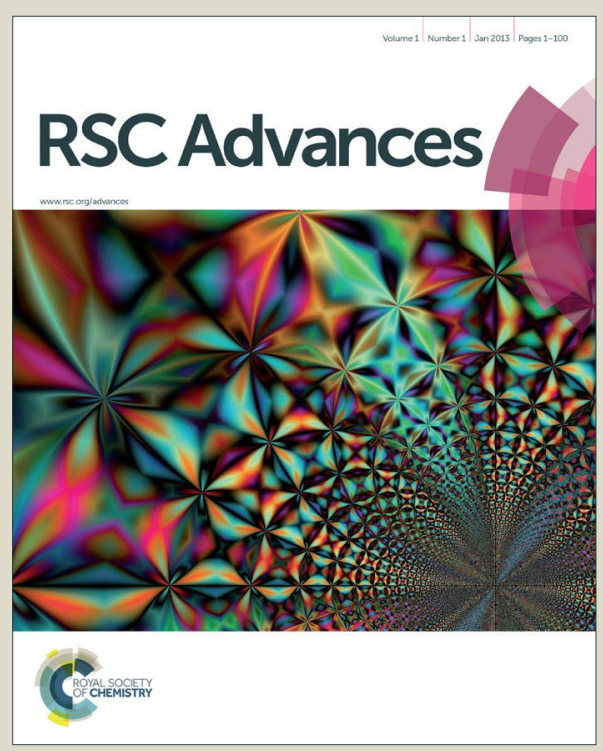

This is an Accepted Manuscript, which has been through the Royal Society of Chemistry peer review process and has been accepted for publication.

Accepted Manuscripts are published online shortly after acceptance, before technical editing, formatting and proof reading. Using this free service, authors can make their results available to the community, in citable form, before we publish the edited article. This Accepted Manuscript will be replaced by the edited, formatted and paginated article as soon as this is available.

You can find more information about Accepted Manuscripts in the Information for Authors.

Please note that technical editing may introduce minor changes to the text and/or graphics, which may alter content. The journal's standard Terms \& Conditions and the Ethical guidelines still apply. In no event shall the Royal Society of Chemistry be held responsible for any errors or omissions in this Accepted Manuscript or any consequences arising from the use of any information it contains. 


\title{
Journal Name
}

\section{Affinity adsorbents for proline-rich peptide sequences: a new role for WW domains}

Received,

Accepted

DOI: $10.1039 / x 0 x \times 00000 x$

www.rsc.org/

\begin{abstract}
A.M.G.C. Dias ${ }^{a}$, R. dos Santos ${ }^{a}$, O. Iranzo*b ${ }^{\text {b }}$ and A.C.A. Roque* ${ }^{a}$
The WW domain derived from human Yes-associated protein (hYAP65_WW) recognizes proline-rich peptides. The structural and chemical robustness of WW domains makes them appealing candidates to target and capture these peptides in affinity purification processes. In this work, the chemical synthesis of the hYAP65_WW domain containing a terminal cysteine for oriented coupling onto the chromatographic matrix was successfully achieved by fragments solution condensation reaction and by incorporation of pseudoproline dipeptide units. Both strategies yielded a hYAP65_WW protein with the characteristic WW domain folding. The purified hYAP65_WW domain was immobilized in a chromatographic matrix and tested for binding to a proline-rich peptide. The adsorbent bound $92 \mathrm{ng}$ of peptide/mg of support and the elution was particularly efficient employing low $\mathrm{pH}$ or an increase in salt concentration. This work sets the ground for the application of WW domains as affinity reagents towards the capture and elution of peptides and proteins rich in proline sequences.
\end{abstract}

\section{Introduction}

Protein-protein interactions are critical for cellular regulation ${ }^{1}$, as signal transduction pathways are mediated by the recognition of specific peptide sequences by proteins, in particular sequences rich in Proline residues (Pro).

Proline is a peculiar amino acid: the pyrrolidine ring confers rigidity to Pro-rich sequences and induces particular conformations. Despite its hydrophobic character, Pro also has an electron rich carbonyl group turning it into an exceptional hydrogen bond acceptor ${ }^{2,3}$. Peptides with compositions of PXPXPXP or PPXPPXPP (X represents any amino acid), assemble into a so called PPI or a PPII helix turn formed by rotation of three residues, which forms a structural feature specifically recognized by different protein domains ${ }^{2}$ with affinity binding constants ranging from $n M$ to $\mu M^{4}$. Pro-rich peptides and proteins are very frequent in humans ${ }^{1}$, other animals (e.g. mouse), plants or bacteria (e.g. membrane proteins in Escherichia coli) ${ }^{5}$.

The isolation and purification of Pro-rich peptides and proteins enables their further characterization and additional

a. UCIBIO, REQUIMTE, Departamento de Química, Faculdade de Ciências e Tecnologia, Universidade Nova de Lisboa, Campus Caparica, 2829-516 Caparica, Portugal, Fax: (+351) 212948550

${ }^{b .}$ Aix Marseille Université, Centrale Marseille, CNRS, iSm2 UMR 7313, 13397 Marseille, France.

† Footnotes relating to the title and/or authors should appear here.

Electronic Supplementary Information (ESI) available: See DOI: $10.1039 / x 0 \times x 00000 x$ applications (e.g. study of molecular disease mechanisms ${ }^{6}$ and targets for drug design ${ }^{7}$ ). Purification of Pro-rich proteins and peptides is often cumbersome and based on affinity tag technologies or individually optimised protocols ${ }^{8-10}$.

Affinity chromatography represents an attractive strategy to isolate target molecules from a complex mixture, as this strategy can capture even very weak binders, which can be eluted and recovered for further identification and characterization $^{11}$.

Peptides containing Pro-rich sequences are recognized by different families of domains including $\mathrm{SH} 3$ domain (Srchomology 3$)^{12}$ and WW domains ${ }^{13}$. WW domains possess 38 40 residues in length, with two tryptophan (W) residues spaced by 20-22 amino acids, which assemble on a three $\beta$ sheet structure ${ }^{14}$. These motifs are present in 200 multidomain proteins and are usually localized in the recognition region, which is known to mediate protein-protein interactions ${ }^{15}$. They have been classified in five different groups based on their recognition sequences. The human YAP65 WW domain (hYAP65_WW) is derived from the human Yes-associated protein, a proto-oncogene, and is representative of Group I by recognizing PPX-Y, where $X$ represents any amino acid ${ }^{16,17}$. This domain has been associated to regulatory pathways important for cell growth and proliferation ${ }^{18}$. It recognizes the peptide sequence EYPPYPPPPYPSG found in p53 (PY peptide, residues 742 to 754 of p53 binding protein-2; in bold are the main amino acids recognized by the WW domain) ${ }^{19}$. In this work the potential of hYAP65_WW to create affinity 
adsorbents for the recognition and capture of Pro-rich peptides, in particular those derived from p53, was assessed.

\section{Results and discussion}

\section{In silico studies - Stability and Affinity}

The hYAP65_WW domain possesses 44 residues in length (hYAP65_WWnativeFL). We shortened the sequence to focus on the amino acids crucial for recognition and folding, generating a smaller version of hYAP65_WW domain with 38 residues in length (hYAP65_WWnative). A Cys residue was also introduced at the $\mathrm{N}$-terminal to facilitate coupling to the chromatographic support (hYAP65_WWmutated) (see Figure 1 A).

Molecular Dynamics (MD) simulations were employed to evaluate the stability of the hYAP65_WWmutated in comparison with the native structures. In Figure $1 \mathrm{~B}$, the Root Mean Square Fluctuation (RMSD) shows that the three structures considered in this study become more stable after $25 \mathrm{~ns}$, and this behaviour is maintained until the end of the simulation. In addition, the Root Mean Square Fluctuation (RMSF) (Figure $1 \mathrm{C}$ ) demonstrates that the structure hYAP65_WWmutated has lower flexibility in the overall structure compared with the other sequences, but maintains the high flexibility in loop I, known to be important for target recognition in WW domains. In all structures a higher flexibility was observed for the residues at the $\mathrm{N}$ and $\mathrm{C}$ terminals, with RSMF values of 0.6 to $0.8 \mathrm{~nm}$ as opposed to the other residues in the sequence showing RMSF values between 0.2-0.4 nm. This information can be visualized in the B-factor analysis (Figure $1 \mathrm{D}$ ), which indicates in a colour code the degree of flexible regions (dark blue - less flexibility, blue, green, yellow until red - high flexibility). In Figure 1 C, hYAP65_WWmutated shows a dark colour except in loop $\mathrm{I}$ and at the $\mathrm{N}$ and $\mathrm{C}$ terminals which appear in light blue colour. From the in silico studies it is also clear the formation of hydrophobic pockets between Trp39, Phe29, Pro42 and Trp19, Pro12, Pro14 and Pro42, which are important for the maintenance of the WW domain folding as described in the literature ${ }^{19}$. During the time of the simulation the hydrogen bonds interactions were analysed and the most prevalent in all structures of hYAP65_WW are compared in Figure S1 A. In Figure S1 B it is possible to observe that the most prevalent hydrogen bonds correspond to interactions between the $\beta$-sheets and also in the $C$ terminal region of the hYAP65_WW. Overall, hydrogen bonds and hydrophobic interactions contribute for the folding of the WW domain.

Molecular docking studies were then conducted to assess the interaction between hYAP65_WWmutated and a small version of the native peptide recognised by the hYAP65_WW domain. The peptide tested, PPPPYPAW, was derived from the p53 protein with the recognition sequence in bold, an Ala (spacer) and a Trp (fluorescent probe). The docking calculation yielded 41 clusters with estimated binding energy between -8.74 and $2.67 \mathrm{kcal} / \mathrm{mol}$. The best solution was presented in Run 111 (78 conformations out of 256 runs) with an estimated $K_{D}$ of $3.62 x$ $10^{-7} \mathrm{M}$ (Figure $2 \mathrm{~A}$ ). This value is lower than the literature reports for the full length peptide where a $K_{D}$ of $5.99 \times 10^{-6} \mathrm{M}$ was experimentally observed ${ }^{19}$. In this docking solution, the peptide is recognized by a hydrophobic cluster formed by several amino acids from the $\beta$-sheets of hYAP65_WWmutated. The Tyr in the peptide PPPPYPAW is recognized through a groove formed by Tyr28 and Trp39, as previously described by Koepf et al ${ }^{19}$. In this conformation the hydrophobic interactions between the Tyr and Trp28 and also the fluorescent probe with Tyr28 could be relevant, as the amino acids are in close proximity $(\sim 4 \AA \AA)$. In the second best docking conformation, Run 142 with $\mathrm{K}_{\mathrm{D}}$ of $2.18 \times 10^{-7} \mathrm{M}$, the Tyr of the peptide is close to His32 with possible formation of hydrogen bonds (Figure $2 \mathrm{~B}$ ). This is an important interaction already described in the literature for recognition between PPXY peptides and WW domains ${ }^{13}$.

\section{Solid-Phase Peptide Chemical Synthesis}

The hYAP65_WWmutated peptide was produced chemically using Fmoc-based chemistry and an automated microwave peptide synthesizer. A standard protocol for synthesis of hYAP65_WW domain was tested. The crude peptide obtained was analyzed by reverse-phase HPLC and the chromatogram showed several major peaks (Figure S2) indicating a very complex mixture that will be very difficult to purify. For this reason, new strategies were needed to improve the synthesis. WW domains possess a characteristic secondary structure composed by three $\beta$-sheets which increases the tendency for aggregation during synthesis, thereby reducing the coupling efficiency and yielding complex mixtures hard to purify. To overcome this problem, several strategies are presented in the literature: namely the use of different solid-supports, e.g. Poly(ethyleneglicol) (PEG) based resins ${ }^{20}$; the change of solvents ${ }^{21}$; the incorporation of special amino acid units during synthesis, e.g. pseudoproline dipeptide units, depsipeptides ${ }^{22}$; or two or more fragments condensation, using for example native chemical ligation ${ }^{23}$.

The hYAP65_WWmutated peptide was produced through two different strategies: solution condensation reaction of two fragments (SCR) and incorporation of pseudoproline dipeptide units during full peptide synthesis (PP) (Figure 3). For the SCR strategy, two different resins were selected to synthesize the protected fragments (Frag 1 in Amide Sieber resin (17 residues) and Frag 2 in $\mathrm{H}$-Gly2-Cl-Trityl resin (21 residues)) with the required free $\mathrm{N}$ and $\mathrm{C}$ terminals for the subsequent condensation reaction (Figure $3 \mathrm{~A}$, see reaction details in experimental section). After deprotection, the crude hYAP65_WWmutated_SCR peptide was purified by preparative HPLC and characterized by ESI-MS (Figure 3E). In the PP synthesis protocol, a PEG-based resin and two pseudoproline units were used (see Figure $3 \mathrm{~B}$ for their location), following a recently described method ${ }^{24}$. The peptide hYAP65_WWmutated_PP was also purified by preparative HPLC and characterized by ESI-MS (Figure 3F). 


\section{Journal Name}

\section{ARTICLE}

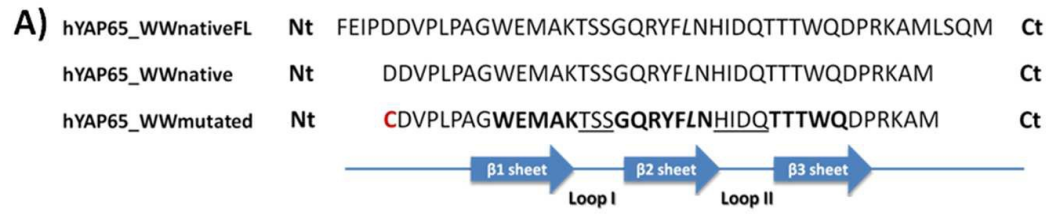

B)

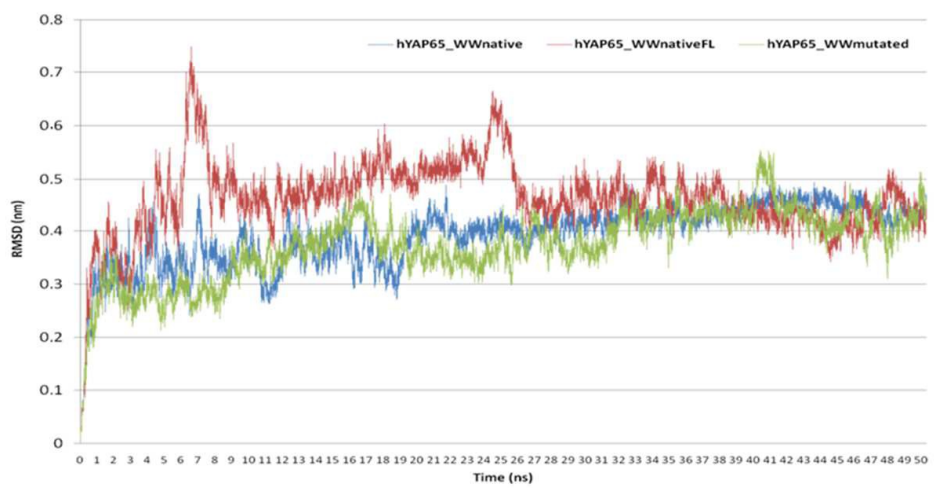

C)
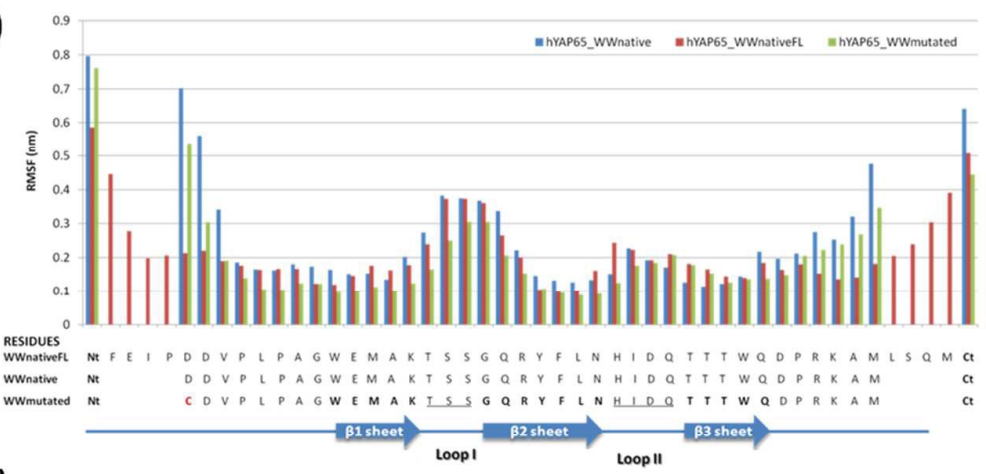

D)

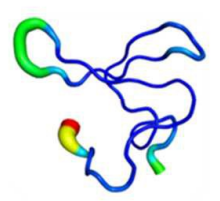

hYAP65_WWnativeFL

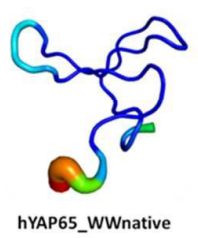

Figure 1- Analysis of molecular dynamics results for three structures of hYAP65_WW domain. A) Sequences used in the in silico studies derived from PDB databank code $1 \mathrm{JMQ}$ sequence, in the sequences K 30 was replaced by L; B) RMSD (Root Mean Square Deviation) analysis; C) RMSF (Root Mean Square Fluctuation) analysis; D) B-factor analysis representation (figures produced using PyMol software)

\section{Circular Dichroism studies}

Circular Dichroism (CD) spectroscopic studies were performed to determine the structure and stability of the chemically synthesised hYAP65_WWmutated_SCR and hYAP65_WWmutated_PP. The spectra were recorded in the Far-UV region to check for the characteristic signals of the WW domains. These proteins have a three $\beta$-sheet structure showing a maximum positive ellipticity at $230 \mathrm{~nm}$ and a maximum negative ellipticity at $206 \mathrm{~nm}$ in the CD spectra (Figure 4). Figures $4 \mathrm{~A}$ and $4 \mathrm{C}$ show the $\mathrm{CD}$ spectra obtained for hYAP65_WWmutated_SCR and hYAP65_WWmutated_PP, respectively, at $4{ }^{\circ} \mathrm{C}$ and $\mathrm{pH} 6$. In both cases, a maximum positive ellipticity at $230 \mathrm{~nm}$ was observed, as expected for a 
WW domain ${ }^{19}$. In addition, temperature denaturation experiments were performed to determine the stability of the peptides. The change in ellipticity at $230 \mathrm{~nm}$ was monitored as the temperature increased from $4{ }^{\circ} \mathrm{C}$ to $88{ }^{\circ} \mathrm{C}$ and vice-versa

A)

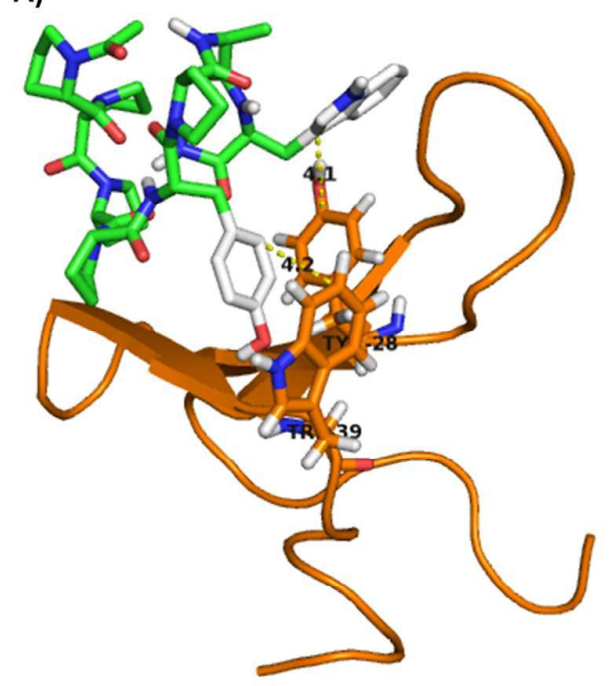

(Figure S3 A and B). The CD melting curves were fitted to a two state-model, using the equation described by Koepf et $a l^{19}$, to determine the temperature of melting $\left(T_{m}\right)$ of the two hYAP65_WW.
B)

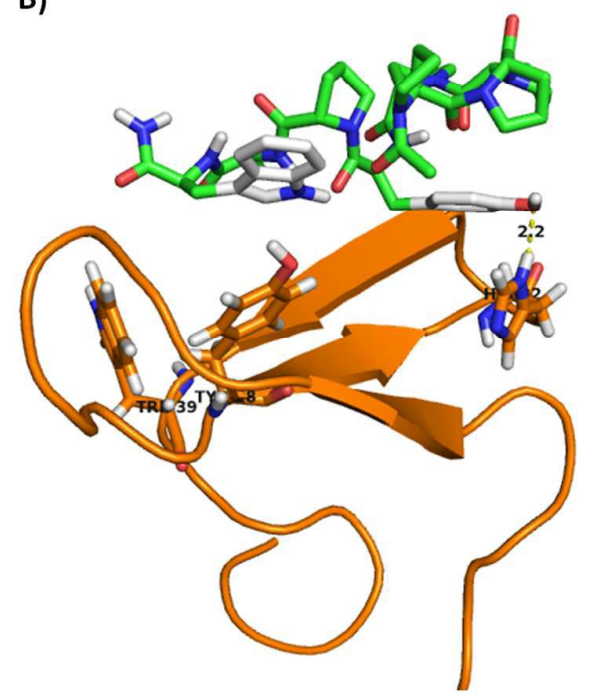

Figure 2 - Best docking results for hYAP65_WWmutated and PPPPYPAW peptide. A) Cluster with 78 similar conformations out of 256 possible conformations, estimated binding energy of $-8.74 \mathrm{Kcal} / \mathrm{mol}$. The interactions between the peptide Tyr or Trp and the Tyr28 and Trp39 are represented; B) Cluster with 43 similar out of 256 possible conformations, estimated binding energy of $-6.36 \mathrm{Kcal} / \mathrm{mol}$. The interaction between the peptide Tyr and the His 32 of the hYAP65_WWmutated is represented (2.2A distance between Tyr OH-group and NH-group in the imidazole ring of His32). Structures produced using PyMol software.

The $T_{m}$ determined by Koepf et al for the peptide hYAP65_WW (57aa) was $48.9 \pm 0.6^{\circ} \mathrm{C}^{19}$. In our studies the $\mathrm{T}_{\mathrm{m}}$ determined was $31.42 \pm 2.95{ }^{\circ} \mathrm{C}\left(R^{2}=0.996\right)$ and $28.52 \pm 2.66{ }^{\circ} \mathrm{C},\left(R^{2}=\right.$ 0.993) for hYAP65_WWmutated_SCR and hYAP65_WWmutated_PP, respectively (Figure 4B and D; Figure $3 \mathrm{~S} A$ and $B$ ). These data indicate a loss of thermal stability in the smaller versions of the hYAP65 (38 aa) with respect to the full-length hYAP65 WW domain (57 aa). Nonetheless, the CD spectra show that hYAP65_WWmutated_SCR and hYAP65_WWmutated_PP structures still maintained the characteristic folding of a WW domain and the unfolding state is totally reversible for both peptides.

\section{Immobilization of hYAP65_WWmutated and Affinity Studies}

As the hYAP65_WW domain recognizes Pro-rich peptides we aimed to test if the smaller WW domain versions chemically produced, still maintained the recognition ability after covalent immobilization on a matrix. For that purpose, we immobilized hYAP65_WWmutated_PP onto cross-linked agarose beads using Sulfo-SMCC chemistry $(54 \%$ immobilization yield; $2.42 \times 10^{-3} \mu \mathrm{mol}$ hYAP65_WWmutated per $\mathrm{mg}$ of support). The novel affinity adsorbent (hYAP65_WWAg) was tested for binding to a Pro-rich peptide (PPPPYPAW). As these assays were performed at $23^{\circ} \mathrm{C}$, we considered that $30 \%$ of the peptide was folded, as described in the experimental section. The hYAP65_WWAg bound $92.1 \pm$ $20.9 \mathrm{ng}$ of peptide/mg support (Table 1), which is 2.4 times higher than the negative control (unmodified agarose). Two peptides without Pro-rich sequences and with distinct hydrophilicity and charge - NNNNNN and RKRKRK - were tested as controls for binding to the modified agarose. No binding was observed for these peptides.

Two different elution conditions were then tested to recover the Pro-rich peptide bound (Table 1): a) an increase in ionic strength, by a step change of $\mathrm{NaCl}$ concentration from $0.5 \mathrm{M}$ to $1 \mathrm{M}$ and $\mathrm{b}$ ) a change in $\mathrm{pH}$ buffer, by using a $\mathrm{pH} 3$ buffer (10 $\mathrm{mM}$ Glycine-HCl) followed by a $\mathrm{pH} 10$ buffer (10 mM CAPS buffer, $100 \mathrm{mM} \mathrm{NaCl}$ ). The recovery of the peptide was more efficient when employing a decrease in $\mathrm{pH}(\mathrm{pH} 6$ to $\mathrm{pH} 3$ ), with $68 \%$ recovery yield. This can be explained by the interactions established between the OH-group of the Tyr in the peptide and the $\mathrm{NH}$-group in the imidazole ring of His32 (from WW domain) (an interaction with a distance of $2.2 \AA$, Figure $2 \mathrm{~B}$ ). At $\mathrm{pH} 3$ the imidazole $\mathrm{NH}$-group has a positive charge $(\mathrm{pKa}=6)$ which weakens the interaction with the $\mathrm{OH}$ group of Tyr, thus facilitating the elution of the peptide. The elution observed at a low $\mathrm{pH}$ can also be due to a decrease in WW folding - it was recently reported that at $\mathrm{pH} 3$ the $\mathrm{WW}$ stability is decreased, yet this behaviour is reversible ${ }^{25}$. At $\mathrm{pH} 10$, the $\mathrm{OH}$-group from the Tyr residue is deprotonated and there is no possibility to form hydrogen bonds with the imidazole $\mathrm{N}$ from the imidazole 
ring of His 32. Consequently, this $\mathrm{pH}$ condition is also a viable condition for elution. Therefore, extremes of $\mathrm{pH}(3$ or $>10)$ would be good to be used for elution, due to the disruption of the His32 interaction with Tyr of PPPPYPAW.

Recovery using a salt gradient was also possible, in particular when employing a high salt concentration solution (1 $\mathrm{M} \mathrm{NaCl}$ ). By increasing the salt concentration the hydrophobic effect is increased as the salt in the buffer reduces the solvation of sample solutes and hydrophobic regions become more

\section{A)}

hYAP65_WWmutated_SCR Nt CDVPLPAGWEMAKTSSGQRYFLNHIDQTTTWQDPRKAM Ct

\section{Acetyl-CDVPLPAGWEMAKTSSG - $\mathrm{COOH}$ NH2 - QRYFLNHIDQTTTWQDPRKAM - Amide}

B) FRAG 1

FRAG 2

hYAP65_WWmutated_PP NT CDVPLPAGWEMAKT X2 GQRYFLNHID $\times 1$ TTWQDPRKAM Ct
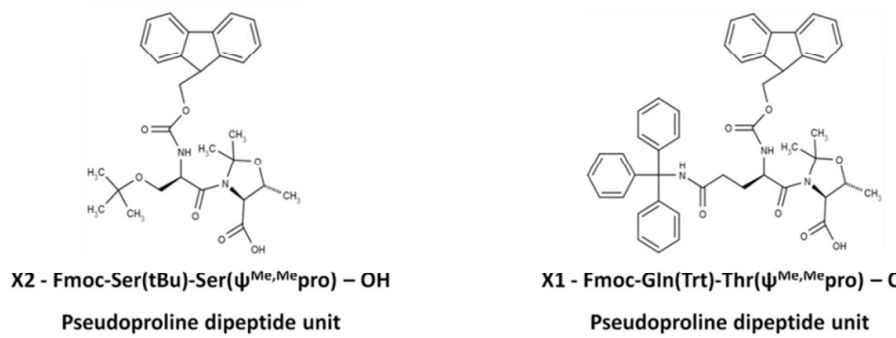

X1 - Fmoc-GIn(Trt)-Thr( $\Psi^{\text {Me,Me }}$ pro $)$ - OH

Pseudoproline dipeptide unit

C)

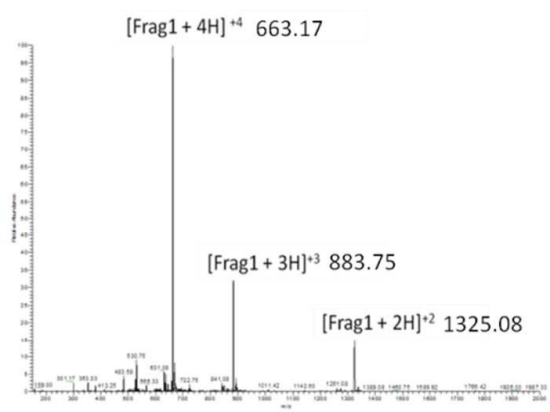

E)

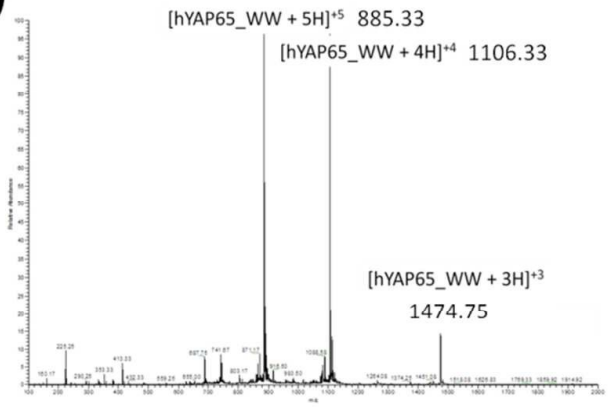

D)

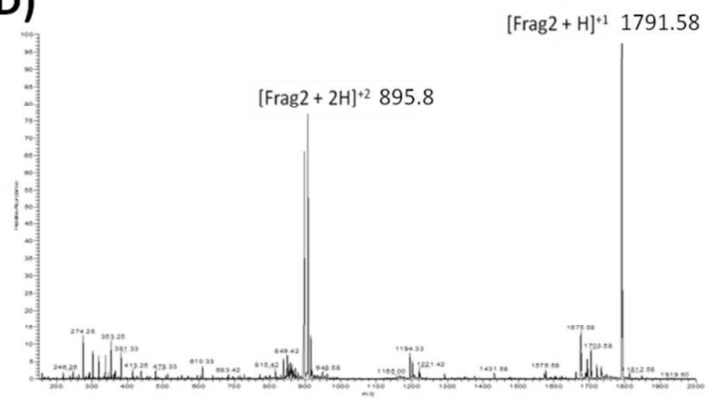

F)

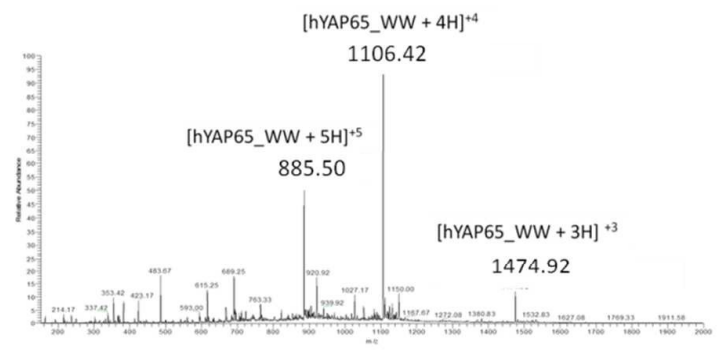

Figure 3 - Nomenclature and amino acid sequences for different hYAP65_WW domain used in this work. A) Solution Condensation Reaction (SCR); B) Synthesis using Pseudoprolines (PP), where $\mathrm{X}_{1}$ and $\mathrm{X}_{2}$ are pseudoproline units; amino acids in italic needed special couplings and for amino acids in green and underlined, a capping step was added. The structures were designed using Marvin Beans version 6.3.0 (ChemAxon). Peptides were purified using preparative HPLC, characterized by ESI-MS in positive mode (for details see ${ }^{24}$ ). C) Frag1-SCR: $[\text { Frag1 }+1]^{+1}$ calc $=2649 \mathrm{Da}$. D) Frag2-SCR: $[$ Frag2 $+1 \mathrm{H}]+1_{\text {calc }}=1791 \mathrm{Da}$. E) hYAP65_WWmutated_SCR peptide: $[\text { YAP65 }+1 \mathrm{H}]^{+1}$ calc $=4421 \mathrm{Da}$. F) hYAP65_WWmutated_PP peptide: $[\text { YAP } 65+1 \mathrm{H}]^{+1}$ calc $=4421 \mathrm{Da}$. 


\section{Journal Name}

\section{ARTICLE}

A)

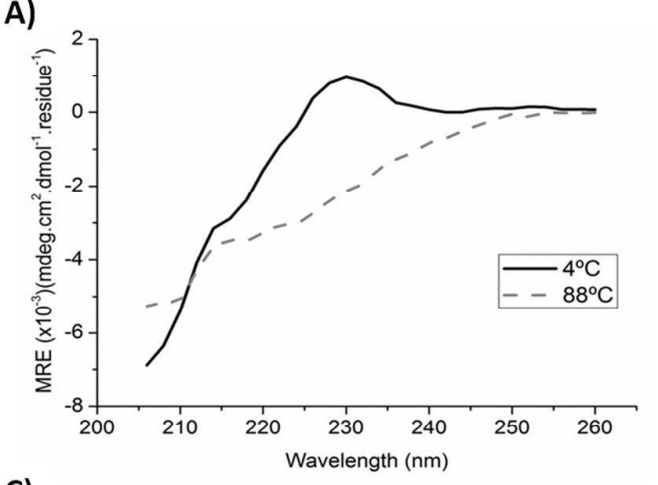

C)

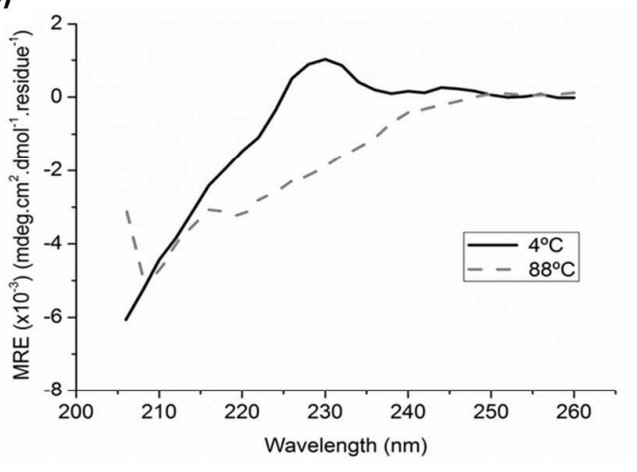

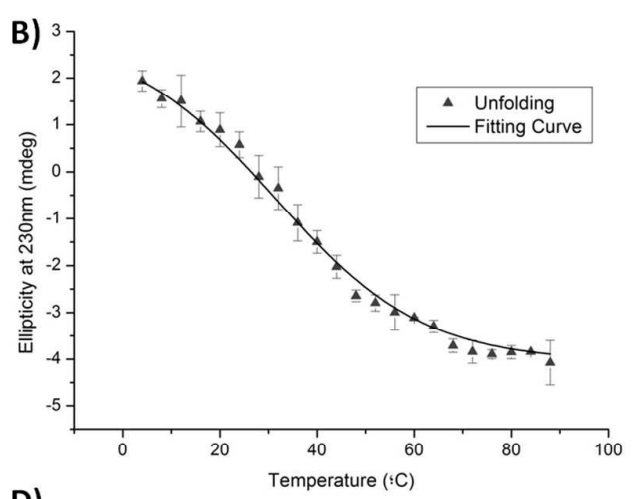

D)

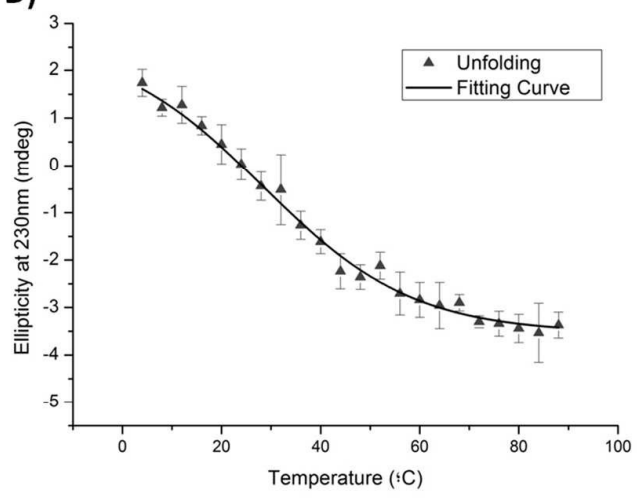

Figure 4 - Circular Dichroism studies. A) Far-UV CD spectra at 4 and $88^{\circ} \mathrm{C}$, hYAP65_WWmutated_SCR; B) Unfolding and Fitting curve between 4 and $88^{\circ} \mathrm{C}$, hYAP65_WWmutated_SCR; C) Far-UV CD spectra at 4 and $88^{\circ} \mathrm{C}$, hYAP65_WWmutated_PP; D) Unfolding and Fitting curve between 4 and $88^{\circ} \mathrm{C}$, hYAP65_WWmutated_PP.

Table 1 - Results of the purification studies between hYAP65_WWAg and peptide PPPPYPAW.

\begin{tabular}{|c|c|c|c|c|c|}
\hline \multirow{2}{*}{ Binding } & ng peptide bound/mg support ${ }^{\mathrm{a}}(\mathrm{n}=12)$ & \multicolumn{4}{|c|}{$92.1 \pm 20.9$} \\
\hline \multirow{2}{*}{ Elution } & & $\mathbf{0 . 5 M ~ N a C l}$ & $\mathbf{1 M ~ N a C l}$ & pH3 & pH10 \\
\cline { 2 - 6 } & \% Recovery $^{\mathrm{b}}(\mathrm{n}=2)$ & $7.4 \pm 1.5$ & $55.1 \pm 7.9$ & $68.2 \pm 1.6$ & $34.2 \pm 0.6$ \\
\hline
\end{tabular}

Note: ${ }^{a}$ Peptide Bound Mass / Support Mass (ng/mg) $=$ (Peptide Mass Loaded - Peptide Mass Unbound) $/$ Support Mass; ${ }^{\mathrm{b}} \%$ Recovery $=($ Peptide Mass Eluted $*$ 100)/ Peptide Mass Bound.

Static partitioning equilibrium studies adjusted to a Hills isotherm model were employed to assess the values of $q_{\max }$ (1471 $\pm 462 \mathrm{ng}$ peptide bound/ $\mathrm{mg}$ support) and the dissociation constant $\left(K_{D}=1.3 \times 10^{-4} \mathrm{M}\right.$ ) (see Figure 5 and Table 2). The $K_{D}$ value between the peptide and immobilised $W W$ is higher than that described in the literature namely for the interaction between the peptide EYPPYPPPPYPSG and WW free in solution $\left(K_{D}=5.99 \times 10^{-6} \mathrm{M}\right)^{19}$. The difference in the results can be due to the immobilization of the WW domain in the agarose matrix. It is known that the spacer arm between the affinity ligand and the resin, the chemistry employed for the immobilization, and the nature of the solid support, can all have an effect on the dissociation constant observed in solidphase. Another aspect that can contribute for the observed 
differences is the fact that the target peptide used in this work is smaller than the one described by Koepf et al. As previously described by Dalby et $a l^{26}$, the difference in binding capacity can be influenced by the residues that are at the edges of the region that is being recognized, in this case the PPPPYP. Still, a $K_{D}$ in the range of $10^{-4} \mathrm{M}$ is desirable in affinity chromatography applications as it facilitates the recovery of the target peptides and proteins.

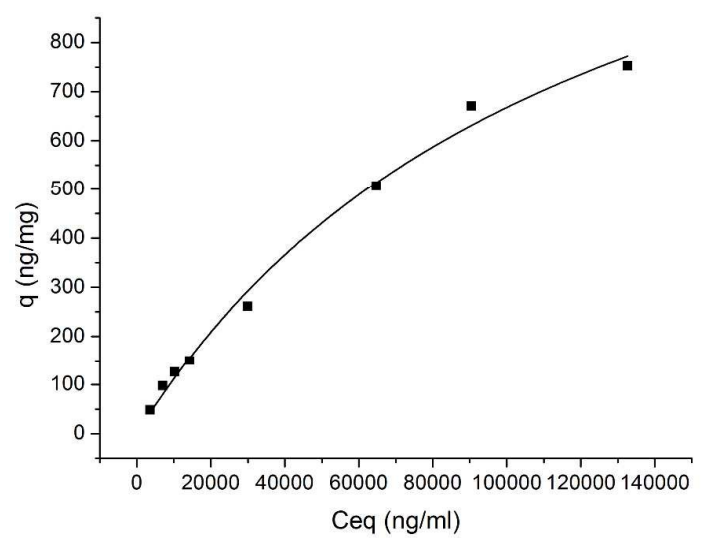

Figure 5 - Characterization of binding between hYAP65_WWAg and peptide PPPPYPAW. Solid line represents the fit to the Hills equation with a $n_{H}=1$, $R^{2}=0.999$.

Table 2 - Characterization of binding between hYAP65_WWAg and peptide PPPPYPAW. Parameters determined by fitting the experimental data to the Hills equation.

\begin{tabular}{|c|c|c|}
\hline \multirow{2}{*}{$\begin{array}{c}\text { Binding } \\
\text { Characterization }\end{array}$} & $\mathrm{q}_{\max }$ (ng peptide bound/mg support) & $1471 \pm 462$ \\
\cline { 2 - 3 } & $\mathrm{K}_{\mathrm{D}}(\mathrm{M})$ & $1.3 \times 10^{-4} \pm 7.9 \times 10^{-5}$ \\
\hline
\end{tabular}

\section{Conclusions}

In this work we demonstrated the application of hYAP65 WW domain as a novel affinity ligand for the purification of Pro-rich peptides. The hYAP65_WW is an interesting affinity protein due to its accessible chemical synthesis. This protein can be used for the purification of Pro-rich peptides using mild conditions for binding and a $\mathrm{pH}$ variation for elution. Thus this domain can be explored for biotechnology applications, namely affinity purification for the enrichment of proline rich peptides and its further integration in proteomic studies.

\section{Experimental}

\section{In Silico Studies}

Molecular Modeling Studies - Structures preparation. The structure of hYAP65_WW was selected from Protein Data Bank (PDB) code: 1 JMQ ${ }^{19}$. The sequence comprising the amino acid residues 5 to 49 was included in the studies. A mutation in residue Lys 30 to Leu was also considered to revert the mutation performed by Koepf et al into the native sequence (hYAP65_WWnativeFL, 45 aa length). In our studies we used a shorter sequence limited to the 9 to 46 residues (hYAP65_WWnative, 38 aa length). Additionally, we performed a mutation in the hYAP65_WWnative sequence by changing Met9 to Cys (YAP65_WWmutated, 38 length), to facilitate the immobilization on the chromatographic matrix.

Molecular Dynamics - Stability studies. Molecular dynamics (MD) were carried out on the GROMACS 4.5 .5 simulation package ${ }^{27}$ running in parallel on the in-house Sun Grid Engine (SGE) high performance computer cluster. The structures of each hYAP65_WW were placed in an octahedral box with a cut off distance between the peptide and the box edges of $10 \AA$ and filled with an explicit SPCE water model. Counter ions of chloride were added, in order to neutralize the global charge of the system. The united-atom force field GROMOS $43 a 1{ }^{28}$ was applied. The simulation parameterization is described in detail in Dias et al for human Pin1 WW domain ${ }^{24}$. Each system was simulated for 50 ns. The visualization softwares PyMol $1.3^{29}$ and VMD $1.9^{30}$ were used to identify the interactions established between the residues of the structures, based on a cut-off distance criteria of $3.2 \AA$ for $\mathrm{H}$ bond interactions between donor and acceptor atoms.

Docking Studies - Affinity studies. The affinity studies were conducted between hYAP65_WWmutated structure (receptor) and PPPPYPAW (ligand), a proline-rich peptide derived from the natural ligand of hYAP65_WW ${ }^{19}$. The peptide was designed using Pymol 1.3 software and saved in a pdb file format. The coordinates of receptor and ligand were converted into pdbqt 
file format. The grid parameter files were setup using the AutoDock 4.0.7 tool package ${ }^{31}$. A Cubic grid was defined using grid size [110 80 80]; spacing of $0.375 \AA$ and Grid center coordinates of [-1.354 -6.955 -2.169]. Since the aim of the work was to immobilize hYAP65_WW into a solid support, the box was defined such that the Cys residue in the structure was maintained out of the box. The ligand was free to explore the entire surface of the receptor. The Lamarckian genetic algorithm was used and a maximum number of 256 solutions were tested. The solutions were grouped with a RMS tolerance of $4 \AA$. . After docking, the solutions were analyzed based on an energy criteria - best scored clusters, with lower Estimated Binding Free Energy, and also considering the number of elements. The conformations with lower Binding Free Energy and most frequent were selected. The results were visualized using PyMol 1.3 software.

\section{Peptide Chemical Synthesis and Characterization}

Solid-Phase Peptide Chemical Synthesis. N,N-dimethylformamide (DMF), acetonitrile, dichloromethane (DCM) and $\mathrm{N}$-methylpyrrolidone (NMP) were purchased from Fisher Scientific (Loures, Portugal), N,Ndiisopropylethylamine (DIEA), piperidine, 1-[bis(dimethylamino)methylene]$1 \mathrm{H}-1,2,3$-triazolo[4,5-b]pyridinium 3-oxid hexafluorophosphate (HATU), benzotriazol-1-yl-oxytripyrrolidinophosphonium hexafluorophosphate (PyBOP), trifluoroacetic acid (TFA), thioanisole, 1,2-ethanedithiol, anisole,4(2-Hydroxyethyl)piperazine-1-ethanesulfonic acid (HEPES), 3(cyclohexylamino)-1-propanesulfonic acid (CAPS), 1,4-diaminobutane and sodium chloride $(\mathrm{NaCl})$ were purchased from Sigma-Aldrich (Loures, Portugal). Glycine $>99.5 \%$ was purchase from NZYtech (Lisbon, Portugal). All Fmoc protected amino acids, 2-(1H-benzotriazole-1-yl)-1,1,3,3tetramethyluronium hexafluorophosphate (HBTU) resins and pseudoproline units, were purchased from EMD Biosciences/Merck Biosciences (Darmstadt, Germany). Sulfosuccinimidyl 4-(N-maleimidomethyl) cyclohexane-1-carboxylate (Sulfo-SMCC) and bond-breaker TCEP Solution purchased were from ThermoScientific, Portugal. Sepharose CL-6B was purchased from GE Healthcare Life Sciences, Portugal. The reagents used in these procedures were always high grade.

For SPPS of hYAP65_WWmutated two strategies were considered: the condensation of two fragments of the WW domain in solution - Solution Condensation Reaction (SCR); and the full synthesis using Pseudoprolines units (PP). In the SCR method two fully protected fragments of hYAP65_WWmutated were prepared by microwave assisted SPPS in two different resins $(0.25 \mathrm{mmol}$ scale). Fragment 1 (Frag1 = 21 aa) was assembled on an Amide Sieber resin (substitution $0.69 \mathrm{mmol} / \mathrm{g}$, Novabiochem) to obtain a free $\mathrm{N}$ terminal and an amidated $\mathrm{C}$ terminal protected peptide. Fragment 2 (Frag2 = 17 aa) was synthesized using a $\mathrm{H}$ Gly-2-Cl-Trityl resin (substitution $0.46 \mathrm{mmol} / \mathrm{g}$, Novabiochem) and acetylated at the end to generate a fully protected peptide with a free $C$ terminal and an acetylated $\mathrm{N}$ terminal. Due to the hyperacidic lability of the resin linkers, the temperature of the different steps of the synthesis was lowered (see Table 3 for details) and hydroxybenzotriazole (HOBt) was removed from the coupling reaction mixture. After assembling the peptides, a small aliquot of each was fully deprotected using standard procedures (Frag1: TFA/triisopropilsilane/water (\% $\mathrm{v} / \mathrm{v}=95: 2.5: 2.5), 2 \mathrm{~h}$; Frag2: TFA/thioanisole/1,2-ethanedithiol/anisole (\% v/v=90:5:3:2), 2 h). The crude peptides were analysed by reverse-phase preparative HPLC, using the following conditions: Phenomenex Jupiter Proteo column $(250 \mathrm{~mm} \times$ $21.20 \mathrm{~mm}, 4 \mu, 90 \AA ̊)$ and a linear gradient from $20 \%$ to $50 \%$ B in $25 \mathrm{~min}$ (solvent A (water/TFA, 99.9:0.1 v/v) and solvent B (acetonitrile/water/TFA, 90:9.9:0.1 v/v)). In each case, a major peak was detected which was collected and analyzed by ESI-Mass Spectrometry (ESI-MS). The ESI-MS spectra recorded in the positive mode confirmed the identity of the two fully protected fragments. Subsequently, both protected fragments were cleaved from the acid-labile linker resins. For the 2-Cl-Trityl resin, short treatments of 2 min with $1 \%$ TFA/DCM were carried out. For the Sieber Amide resin, longer treatments $(5 \mathrm{~min}$ ) and higher content of TFA ( $2.5 \%$ TFA/DCM) were required. The solutions were filtered into a vial containing DIEA to neutralize the $\mathrm{pH}$ and those fractions that contained the peptides, as shown by TLC, were combined and the solvent reduced under vacuum. Small volumes of water were used to precipitate the protected peptide. The precipitate was dried using the vacuum pump. Both fragments were used without further purification.

The condensation reaction was carried out using the following procedure. A reaction mixture containing 1.2 eq Frag2, 1.2 eq PyBOP and 4 eq DIEA in DCM was stirred for $5 \mathrm{~min}$ under nitrogen. Afterwards, 1.2 eq. of Frag1 were added. To increase the solubility, the protected Frag1 and Frag2 were dissolved in a minimum amount of DMF before addition into the DCM mixture. After $1 \mathrm{~h}$ reaction, extra 1.2 eq of PyBOP and 4 eq of DIEA were added. The reaction was monitored by analytical reverse-phase HPLC by taking aliquots during the reaction period. The following HPLC conditions were used: Phenomenex Jupiter Proteo column $(250 \mathrm{~mm} \times 4.60 \mathrm{~mm}, 4 \mu$, 90Å) a 30\% Solvent B isocratic flow for 5 min follow by a 10 min linear gradient until 40\% Solvent B (solvent A (water/TFA, 99.95:0.05 v/v) and solvent B (water/TFA, 90.95:0.0.05 v/v)), with $0.6 \mathrm{~mL} / \mathrm{min}$ flow rate. Rt $($ Frag1-Protected $)=3.76 \mathrm{~min}, \mathrm{Rt}($ Frag2-Protected $)=6.10 \mathrm{~min}$ and Rt (Product-Protected) $=6 \mathrm{~min}$. The reaction took place for $10 \mathrm{~h}$ at room temperature under nitrogen atmosphere and magnetic stirring. This reaction time was chosen since similar strategies described in the literature demonstrated that increasing reaction time to $24 \mathrm{~h}$ did not improve the reaction yield ${ }^{32}$. Indeed, in our case, longer reaction times produced a mixture of compounds as observed by HPLC analysis (results not shown). At the end of the reaction, solvents were removed and an yellow oil was obtained, which yielded a white precipitate (protected peptide) upon addition of water. After filtration and drying, the full deprotection reaction 
was carried out using TFA/thioanisole/1,2-ethanedithiol/anisole (\% $\mathrm{v} / \mathrm{v}=90: 5: 3: 2$ ) for $2 \mathrm{~h}$ at room temperature and under nitrogen atmosphere. The resultant crude peptide was purified by reverse-phase HPLC using the following conditions: Phenomenex Jupiter Proteo column, $250 \mathrm{~mm} \times 21.2$ $\mathrm{mm}, 4 \mu, 90 \AA$, linear gradient from $20 \%$ to $50 \%$ solvent B over $25 \mathrm{~min}$ with a flow rate of $10 \mathrm{~mL} / \mathrm{min}$, solvent $A$ (water/TFA, 99.9:0.1 v/v) and solvent $B$ (acetonitrile/water/TFA, 90:9.9:0.1 v/v). The pure peptide was characterized by ESI-MS. The purity of the peptide (hYAP65_WWmutated_SCR) was checked by analytical reverse phase HPLC and it was greater than $95 \%$.

Table 3 - Microwave synthesis conditions and reagents for Trityl Chloride and Sieber Amide resins.

\begin{tabular}{|c|c|c|c|c|}
\hline & REAGENTS & $\begin{array}{c}\text { POWER } \\
\text { (watts) }\end{array}$ & T $\left({ }^{\circ} \mathrm{C}\right)$ & $\begin{array}{c}\text { REACTION TIME } \\
(\mathrm{sec})\end{array}$ \\
\hline Deprotection & $\begin{array}{c}20 \% \\
\text { piperidine/DMF }\end{array}$ & 35 & 50 & 234 \\
\hline Coupling & HBTU/DIEA/DMF & 25 & 50 & 390 \\
\hline $\begin{array}{c}\text { Coupling Arg } \\
\text { (double coupling) }\end{array}$ & HBTU/DIEA/DMF & $0^{\text {a } \text { and } 25^{\mathrm{b}}}$ & 50 & $\begin{array}{c}1950^{\mathrm{a}} \\
\text { and } 400^{\mathrm{b}}\end{array}$ \\
\hline
\end{tabular}

Note: Arginine residues requires double coupling: ${ }^{\text {a }} 1^{\text {st }}$ coupling and ${ }^{b} 2^{\text {nd }}$ coupling.

Pseudoproline units were used to simplify the synthesis protocol by preparing a full length hYAP65_WWmutated peptide. This strategy was applied previously for the synthesis of human Pin1 WW domain ${ }^{24}$. This strategy was feasible because this domain contains Ser and Thr residues located in the middle of the sequence. Consequently, two dipeptide units, Fmoc-GIn(Trt)-Thr( $\psi^{\mathrm{Me}}$, Me pro)-OH and Fmoc-Ser(tBu)-Ser( $\psi^{\mathrm{Me}}, \mathrm{Me}$ pro)-OH were selected for introduction during synthesis (see Figure 3.3 B for specific location). The synthesis ( $0.25 \mathrm{mmol}$ scale) was carried out using a NovaPEG Rink Amide LL resin (substitution $0.23 \mathrm{mmol} / \mathrm{g}$, Novabiochem), which was previously swelled for $30 \mathrm{~min}$ in DMF and directly loaded in the reaction vessel. The protocol for couplings and reaction mixtures was the same as described before ${ }^{24}$. After synthesis the resin was treated with the mixture TFA/thioanisole/1,2-ethanedithiol/anisole ( $\% \mathrm{v} / \mathrm{v}=90: 5: 3: 2)$ for 3 hours at room temperature and under nitrogen to cleave and fully deprotect the peptide. The solution was reduced under a nitrogen stream and cold diethyl ether was added to precipitate the crude peptide which was dissolved in water and lyophilized. hYAP65_WWmutated_PP crude sample was purified by preparative reverse-phase HPLC, using the solvent B mixture described before. The peptide was eluted with a linear gradient of Solvent B ( $20 \%$ to $50 \%$ in $25 \mathrm{~min})$ at a flow rate of $10 \mathrm{~mL} / \mathrm{min}\left(\mathrm{R}_{\mathrm{t}}=20.52 \mathrm{~min}\right)$. The peptide was characterized by ESI-MS and the molecular weight was determined.

Circular Dichroism Studies. Circular Dichroism spectroscopic studies were performed to determine the secondary structure and the stability of the chemically synthesized hYAP65_WWmutated. The studies were performed under a constant flow of nitrogen on a Jasco J-715 spectropolarimeter equipped with a thermostated cell holder and a Peltier bath using $1 \mathrm{~mm}$ path length quartz cells. The stock peptide solutions were prepared in MilliQ water, previously purged with nitrogen, and the concentration was determined by UV-vis spectroscopy using the extinction coefficients of tryptophan $\left(5690 \mathrm{M}^{-1} \cdot \mathrm{cm}^{-1}\right)$ and tyrosine $\left(1280 \mathrm{M}^{-1} \cdot \mathrm{cm}^{-1}\right)$ at $280 \mathrm{~nm}$ in $6 \mathrm{M}$ $\mathrm{GdnHCl}^{33}$. The following experimental conditions were used: all the samples contained $50 \mu \mathrm{M}$ peptide, $10 \mathrm{mM}$ potassium phosphate buffer $\mathrm{pH} 6$ and 100 $\mathrm{mM} \mathrm{NaCl}$. The spectra of the peptides hYAP65_WWmutated_SRC and Pseudoprolines (hYAP65_WWmutated_PP were recorded in the wavelength range of $208-300 \mathrm{~nm}$ at $4^{\circ} \mathrm{C}$ and $88^{\circ} \mathrm{C}$. The temperature denaturation experiments were carried between 4 and $88^{\circ} \mathrm{C}$, with an increase step of $4^{\circ} \mathrm{C}$ and $5 \mathrm{~min}$ equilibration time between temperatures. The following parameters were used during acquisition: $2 \mathrm{~nm}$ scale, continuous scanning, $200 \mathrm{~nm} / \mathrm{min}$ velocity and accumulation of 4 to 8 runs. The peptide refolding was studied from $88^{\circ} \mathrm{C}$ to $4^{\circ} \mathrm{C}$ using the same conditions described before. The molar residue ellipticities (MRE, deg $\mathrm{cm}^{2} \mathrm{dmol}^{-1}$ ) and the Temperature of melting $\left(T_{m}\right)$ were calculated using the equation and protocol described in Dias et al ${ }^{24}$. The spectra were recorded in the Far-UV region to check for the characteristic signals of the WW domains.

\section{Immobilization of hYAP65_WWmutated and Affinity studies}

Immobilization in solid support. For immobilization of hYAP65_WWmutated in the solid support the Sulfo-SMCC chemistry was chosen, as the amine groups in the support will react with the SH group of the peptide's Cys. The solid support used was a commercial cross-linked agarose (Sepharose CL-6B), which was epoxy-activated using the method described in the literature ${ }^{34}$. The epoxy-activated agarose beads ( $23 \mu \mathrm{mol}$ of epoxy groups/g of wet gel) were then aminated by using 5 molar excess conditions of 1,4-diaminobutane for a total volume of $8 \mathrm{~g}$ wet gel. The slurry was incubated overnight at $40{ }^{\circ} \mathrm{C}$ with orbital agitation. After this, the aminated agarose beads were thoroughly washed (about 10x gel volume) with distilled water and the amine content was determined by the Kaiser test ${ }^{35}$ (13 $\mu \mathrm{mol}$ of Amines/g of wet gel). The resin was stored in $20 \%$ ethanol at $4{ }^{\circ} \mathrm{C}$.

To proceed with immobilization of hYAP65_WWmutated in the aminated support, the following solutions were used: an immobilization buffer (50 mM HEPES, $150 \mathrm{mM} \mathrm{NaCl}, 1 \mathrm{mM}$ EDTA pH 7.2) and a buffer to dissolve Sulfo-SMCC (50 mM HEPES pH 7). These buffers were de-aerated using nitrogen flow before use. Sulfo-SMCC was used in a 5 molar excess to the number of amines in the support, this is in accordance with manufacturer indications, to achieve a ratio of $0.5 \mu \mathrm{mol}$ Peptide: $1 \mu \mathrm{mol}$ of aminated support. The support was washed 5 times with $500 \mu \mathrm{L}$ of immobilization buffer. The solution of $9.5 \mathrm{mg}$ Sulfo-SMCC in $950 \mu \mathrm{L}$ of $50 \mathrm{mM}$ HEPES $\mathrm{pH} 7$ was prepared, added to the support and incubated with orbital agitation (30 $\mathrm{rpm}$ ) for $30 \mathrm{~min}$ at room temperature. Meanwhile, a solution of hYAP65_WWmutated $(10 \mathrm{mg} / \mathrm{mL})$ was prepared in immobilization buffer and sonicated for $10 \mathrm{~min}$. To avoid any oxidized Cys in the peptide, bondbreaker TCEP solution reagent was added in a volume ratio of 1:100 peptide/TCEP. After incubation the solution was removed by filtration and 
the support was washed 3 times with deaerated immobilization buffer to eliminate unreacted Sulfo-SMCC. After this, the solution of hYAP65_WWmutated was added to the modified support and incubated for $1 \mathrm{~h}$ in the same conditions described above. The support was washed with immobilization buffer 4 times and a solution of L-Cystein was prepared in the same molar ratio of Sulfo-SMCC and incubated for $30 \mathrm{~min}$ with the support to block non-reacted sites. Afterwards, the support was washed 4 times with immobilization buffer. Finally, to determine the yield of immobilization, all samples obtained during the washing procedure were quantified by intensity fluorescence $\left(\lambda_{\text {excitation }}=280 \mathrm{~nm}\right.$ and $\lambda_{\text {emission }}=340 \mathrm{~nm}$, calibration curve: $y=397501 x, R^{2}=0.99$ and a Gain: 57) using a microplate reader Tecan instrument. The support (hYAP65_WWAg) was saved at $4{ }^{\circ} \mathrm{C}$ in immobilization buffer.

Purification of Pro-rich peptide. The adsorbent hYAP65_WWAg (100 mg wet gel) was regenerated at $4{ }^{\circ} \mathrm{C}$ using regeneration buffer $(0.1 \mathrm{M} \mathrm{NaOH}$ in $30 \%$ isopropanol) and water. The regeneration process was repeated 3 times by alternating the regeneration buffer with water. To remove the supernatant the resin was centrifuged at $10000 \mathrm{rpm}$ for $2 \mathrm{~min}$. The binding buffer used in these studies was $10 \mathrm{mM}$ sodium phosphate, $100 \mathrm{mM} \mathrm{NaCl}$ $\mathrm{pH} 6$, the same buffer used by Koepf et $a l^{19}$ in binding studies with native ligand of hYAP65_WW. The support was equilibrated with binding buffer, until the absorbance of the samples reached $\mathrm{Abs}_{280 \mathrm{~nm}}<0.005$. The peptide PPPPYPAW (Purity $>97 \%$ from CASLO, ApS, Lyngby, Denmark) was reconstituted at $0.20 \mathrm{mg} / \mathrm{mL}$ in binding buffer. This solution $(0.30 \mathrm{~mL})$ was incubated at room temperature $\left(23^{\circ} \mathrm{C}\right)$ for $2 \mathrm{~h}$ with the equilibrated hYAP65_WWAg adsorbent. After incubation, the flow-through was collected and the support was washed 7 times with $0.30 \mathrm{~mL}$ binding buffer. As a negative control, unmodified agarose was also tested in the same conditions. The amount of peptide in all collected samples, flow-through and washes was analyzed by measuring the $\mathrm{Abs}_{230 \mathrm{~nm}}$ and intensity fluorescence $\left(\lambda_{\text {excitation }}=280 \mathrm{~nm}\right.$ and $\left.\lambda_{\text {emission }}=340 \mathrm{~nm}\right)$ in a microplate reader Tecan instrument to determine the amount of PPPPYPAW bound to the support. The same conditions were used to test two peptides without Prorich sequences - NNNNNN and RKRKRK (Purity >97\% from CASLO, ApS, Lyngby, Denmark). The binding results were treated to determine the amount of peptide bound to the support and expressed as ng peptide bound $/ \mathrm{mg}$ support $=$ (ng peptide loaded - ng peptide output $) / \mathrm{mg}$ support, the amount of support was multiplied by $30 \%$ to account for the amount of folded peptide at $23^{\circ} \mathrm{C}$. The elution conditions tested in independent experiments were salt and $\mathrm{pH}$ step gradients: (i) $25 \mathrm{mM}$ HEPES buffer $\mathrm{pH} 7$ with $0.5 \mathrm{M} \mathrm{NaCl}$ followed by $25 \mathrm{mM} \mathrm{HEPES}$ buffer $\mathrm{pH} 7$ with $1 \mathrm{M} \mathrm{NaCl}$; (ii) 10 $\mathrm{mM}$ Glycine- $\mathrm{HCl}$ pH3 followed by $10 \mathrm{mM}$ CAPS buffer, $100 \mathrm{mM} \mathrm{pH} 10$. The supports were washed with each elution buffer 4 times $0.15 \mathrm{~mL}$. The amount of peptide in the elution samples was determined by measuring intensity fluorescence $\left(\lambda_{\text {excitation }}=280 \mathrm{~nm}\right.$ and $\left.\lambda_{\text {emission }}=340 \mathrm{~nm}\right)$ in microplate reader Tecan instrument. The elution results were expressed as the amount of ng peptide eluted/mg support, the amount of support was multiplied by $30 \%$ to account for the amount of folded peptide at $23^{\circ} \mathrm{C}$ and $\%$ Recovery= (peptide mass eluted * 100)/ peptide mass bound.

Static equilibrium studies. Static equilibrium studies were used to determine the dissociation constant $\left(K_{D}\right)$ of the complex formed between the affinity adsorbent and the peptide PPPPYPAW. The hYAP65_WWAg (50 $\mathrm{mg}$ ) was incubated with peptide solutions at different concentrations: 0.2 , $0.15,0.10,0.05,0.025,0.02,0.015$ and $0.01 \mathrm{mg} / \mathrm{mL}$ in a total volume of 0.15 $\mathrm{mL}$. The incubation occurred overnight with agitation $(100 \mathrm{rpm})$ at $23^{\circ} \mathrm{C}$. The flow-through was removed. After that the loading solutions and the flow-through were quantified at $A b_{230 n m}$ to determine the amount of PPPPYPAW bound to the support. To determine the dissociation constant the data was treated and fitted to the Hills model using the following equation:

$$
q=\frac{q_{\max } * C e q^{n}}{K_{D}^{n}+C e q^{n}} \quad \text { Equation } 1.1
$$

where $\mathrm{q}$ - peptide bound mass/support mass (ng/mg); $q_{\max }$ - maximum binding capacity of the support $(\mathrm{ng} / \mathrm{mg}) ; \mathrm{C}_{\mathrm{eq}}$ - concentration at equilibrium concentration of the flow-through samples collected after incubation with support overnight $(\mathrm{ng} / \mathrm{mL}) ; K_{D}$ - dissociation constant $(\mathrm{mg} / \mathrm{mL})$; and $\mathrm{n}$ - Hill coefficient ( $n=1$, non-cooperative binding; $n>1$, positive cooperativity; $n<1$, negative cooperativity) ${ }^{36}$.

\section{Acknowledgements}

A.M.G.C.D. would like to thank Dr. Iris Batalha and Dr. Ricardo Branco for the helpful discussions and technical support in peptide immobilization and in the in silico studies, respectively.

A.M.G.C.D. and R.S. are grateful to Fundação para a Ciência e Tecnologia (FCT) - Portugal for funding through PhD grants SFRH/BD/72664/2010 and PD/BD/105753/2014, the National Network of Mass Spectrometry REDE/1504/REM/2005, project PTDC/EBB-BIO/102163/2008 and PTDC/EBBBIO/118317/2010. This work was supported by the Unidade de Ciências Biomoleculares Aplicadas-UCIBIO which is financed by national funds from FCT/MEC (UID/Multi/04378/2013) and cofinanced by the ERDF under the PT2020 Partnership Agreement (POCl-01-0145-FEDER-007728). Mass Spectrometry data were provided by the Mass Spectrometry Laboratory, Analytical Services Unit, Instituto de Tecnologia Química e Biológica, Universidade Nova de Lisboa.

\section{References}

1 A. A. Morgan and E. Rubenstein, PLoS One, 2013, 8, e53785.

2 L. J. Ball, R. Kühne, J. Schneider-Mergener and H. Oschkinat, Angew. Chemie, 2005, 44, 2852-2869.

W. Gu and V. Helms, 2005, 1754, 232-238.

4 J. a Jadwin, M. Ogiue-Ikeda and K. Machida, FEBS Lett., 2012, 586, 2586-96.

5 M. P. Williamson, Biochem. J., 1994, 297, 249-260. 


\section{Journal Name}

6

J. H. Cho, C. B. Park, Y. G. Yoon and S. C. Kim, Biochim. Biophys. Acta, 1998, 1408, 67-76.

7 M. Srinivasan and A. K. Dunker, Int. J. Pept., 2012, 2012, 1-14.

8 G. S. Bedi and S. K. Bedi, Prep. Biochem., 1995, 25, 119-132.

9 H. Boze, T. Marlin, D. Durand, J. Pérez, A. Vemhet, F. Canon, P. Sami-Manchado, V. Cheynier and B. Cabane, Biophys. J., 2010, 99, 656-665. A. J. Butcher, K. Gaston and P. S. Jayaraman, J. Chromatogr. B, 2003, 786, 3-6.

11 V. S. Rao, K. Srinivas, G. N. Sujini and G. N. S. Kumar, 2014, 2014.

12 B. J. Mayer, J. Cell Sci., 2001, 114, 1253-1263.

13 M. J. Macias, S. Wiesner and M. Sudol, FEBS Lett., 2002, 513, 3037.

14 M. Sudol, H. I. Chen, C. Bougeret, A. Einbond and P. Bork, FEBS Lett., 1995, 369, 67-71.

15 M. Sudol and T. Hunter, Cell, 2000, 103, 1001-1004.

16 H. I. Chen, A. Einbond, S. J. Kwak, H. Linn, E. Koepf, S. Peterson, J. W. Kelly and M. Sudol, J. Biol. Chem., 1997, 272, 17070-17077.

17 H. I. Chen and M. Sudol, Proc. Natl. Acad. Sci., 1995, 92, 78197823.

18 O. Ferrigno, F. Lallemand, F. Verrecchia, S. L'Hoste, J. Camonis, A. Atfi and A. Mauviel, Oncogene, 2002, 21, 4879-4884. E. K. Koepf, H. M. Petrassi, M. Sudol and J. W. Kelly, Protein Sci., 1999, 8, 841-853.

20 B. G. D. la Torre, A. Jakab and D. Andreu, Int. J. Pept. Res. Ther., 2007, 13, 265-270.

21 A. K. Tickler, A. B. Clippingdale and J. D. Wade, Potein Pept. Lett., 2004, 11, 377-384.

22 I. Coin, M. Beyermann and M. Bienert, Nat. Protoc., 2007, 2, 32473256.

23 Z. Fidan, A. Younis, P. Schmieder and R. Volkmer, J. Pept. Sci., 2011, 17, 644-649. A. Dias, O. Iranzo and A. Roque, RSC Adv., 2015, 5, 19743-19751. M. Iglesias-Bexiga, F. Castillo, E. S. Cobos, T. Oka, M. Sudol and I. Luque, PLoS One, 2015, 10, e0113828.

2366-2376.

27 B. Hess, C. Kutzner, D. Van Der Spoel and E. Lindahl, J. Chem. Theory Comput., 2008, 4, 435-447.

28 X. Daura, A. E. Mark and W. F. Van Gunsteren, J. Comput. Chem. Chem, 1998, 19, 535-547.

29 W. DeLano, CCP4 Newsl. Protein Crystallogr., 2002.

30 W. Humphrey, A. Dalke and K. Schulten, J. Mol. Graph., 1996, 14, 33-38.

31 G. M. Morris, D. S. Goodsell, R. S. Halliday, R. Huey, W. E. Hart, R. K. Belew and A. J. Olson, J. Comput. Chem., 1998, 19, 1639-1662.

32 C. Gracia, A. Isidro-Llobet, L. J. Cruz, G. a. Acosta, M. Álvarez, C. Cuevas, E. Giralt and F. Albericio, J. Org. Chem., 2006, 71, 71967204.

33 T. E. Creighton, Protein Structure: a Practical approach, IRL Press at Oxford University, Oxford, 2nd edn., 1997.

34 J. M. Haigh, A. Hussain, M. L. Mimmack and C. R. Lowe, J. Chromatogr. B, 2009, 877, 1440-1452.

35 D. A. Wellings and E. Atherton, in Methods in Enzymology, ed. E. Fields, G. B. Academic Press, San Diego, 1997, p. 54.

36 S. Goutelle, M. Maurin, F. Rougier, X. Barbaut, L. Bourguignon, M. Ducher and P. Maire, Fundam. Clin. Pharmacol., 2008, 22, 633-
648. 


\section{Chemical Synthesis}

\section{Immobilization}
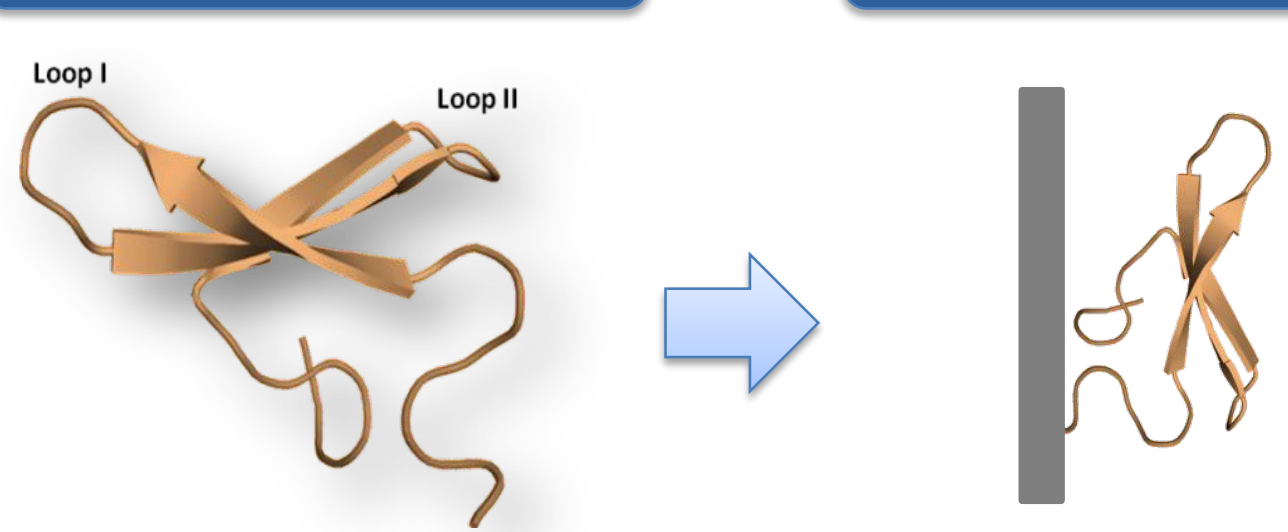

YAP65 WW domain

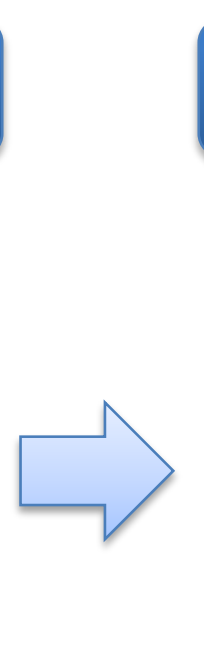

\section{Capture and Elution}

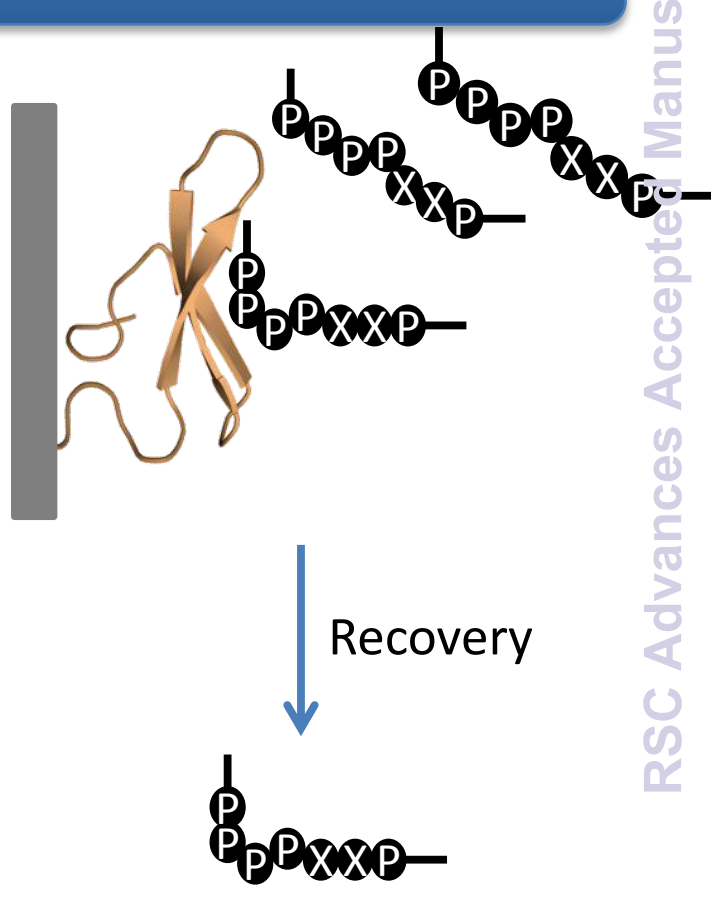

Proline - Rich peptide sequence 